\title{
Anti-helminticos na toxocariase experimental: efeito na recuperação de larvas de Toxocara canis e na resposta humoral
}

\author{
Anthelmintics in experimental toxocariasis: effects on larval recovery of Toxocara canis and on immune response
}

Susana Zevallos Lescano'; Pedro Paulo Chieffi²; Vicente Amato Neto³; Denise Kátia Ikaii; Manoel Carlos Sampaio Almeida Ribeiro ${ }^{5}$

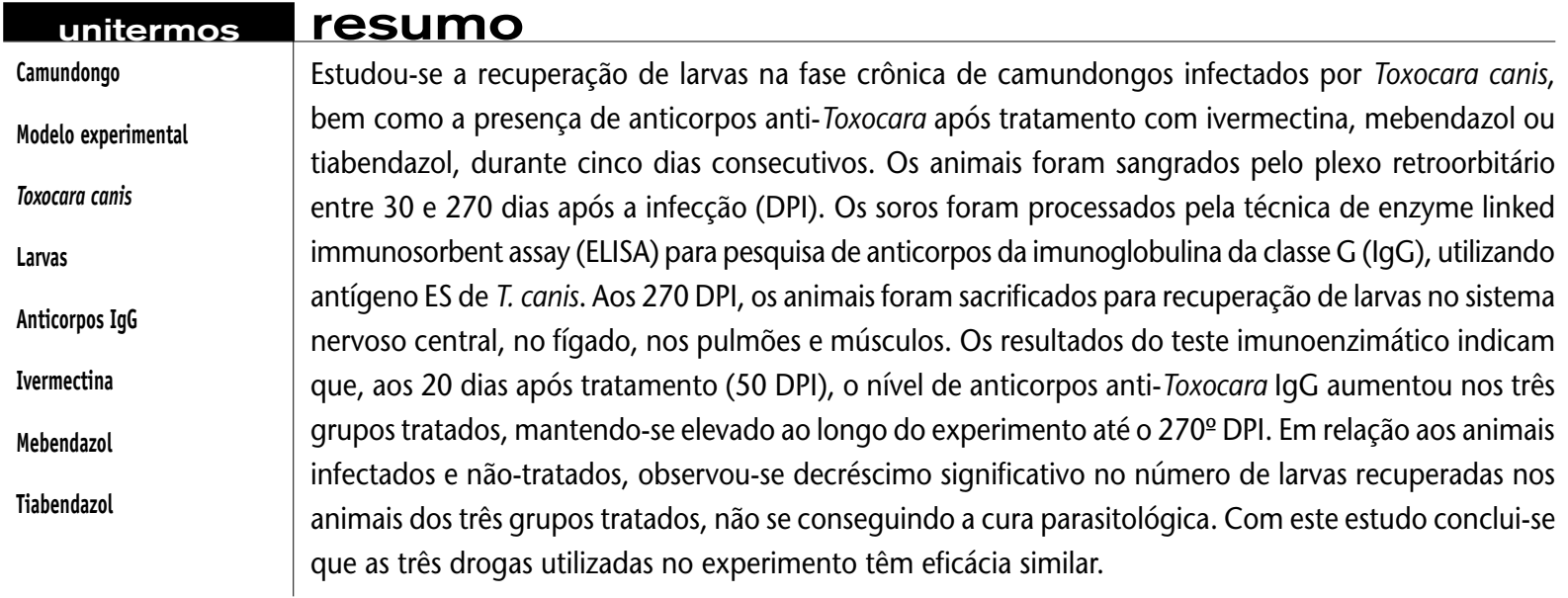

abstract

The effects of treatment with ivermectin, mebendazole or tiabendazole, during five days, on the larval recovery and immune response to Toxocara canis in experimental chronically infected mice were studied. Animals were bled, using the retro-orbital plexus between the $30^{\text {th }}$ and the $270^{\text {th }}$ days post-infection (Dpi), and sera were processed by ELISA technique for IgG antibodies using ES antigen from T. canis. On day 270 all the animals were killed for larval recovery in the central nervous system, liver, lungs and carcass. Immunoenzimatic test results indicate that 20 days after treatment (50 DPI) the anti-Toxocara Ig G antibody level increased in the three treated groups and remained elevated until $270 \mathrm{DPI}$. It was observed a significative decrease in larvae recovered from treated animals when compared to infected but no treated animals with no parasitological cure. The present study shows that the three drugs used in the experiment have similar efficacy.

key words

Mice

Experimental model

Toxocara canis

Larvae

IgG antibodies

Ivermectin

Mebendazole

Tiabendazole

\footnotetext{
1. Doutora em Parasitologia; pesquisadora do Instituto de Medicina Tropical de São Paulo (LIM 06).

2. Professor-titular de Parasitologia da Faculdade de Ciências Médicas da Santa Casa de São Paulo; professor-assistente-doutor da Faculdade de Medicina da Universidade de São Paulo (FMUSP) e do Instituto de Medicina Tropical de São Paulo.

3. Professor-emérito da FMUSP, Laboratório de Investigação Médica/Parasitologia (LIM 46), Hospital das Clínicas da FMUSP.

4. Aprimoranda do LIM 06, Instituto de Medicina Tropical de São Paulo.

5. Professor-assistente da Faculdade de Ciências Médicas da Santa Casa de São Paulo.

Estudo realizado no Laboratório de Imunopatologia da Esquistossomose e Outras Parasitoses (LIM 06) do Instituto de Medicina Tropical de São Paulo/USP.

Trabalho apresentado no XXXVII Congresso da Sociedade Brasileira de Medicina Tropical, realizado de 11 a 15 de março de 2001, em Salvador (BA).
} 


\section{Introdução}

Toxocara canis é um ascarídeo parasita intestinal de canídeos, freqüentemente encontrado em cães domésticos, com distribuição cosmopolita. Seres humanos podem albergar larvas de terceiro estádio desse ascarídeo em seus tecidos, atuando como hospedeiros paratênicos. Em nosso meio, a infecção humana por larvas de $T$. canis é situação freqüente, embora geralmente assintomática. Quando sintomática atinge principalmente crianças. Adultos, em menor número, no entanto, também podem desenvolver a doença ${ }^{(2,17)}$

A terapia para larva migrans visceral (LMV) é principalmente sintomática e direcionada para diminuir a resposta inflamatória provocada por larvas e seus produtos metabólicos nos tecidos do hospedeiro. Anti-helmínticos benzimidazólicos têm demonstrado eficácia moderada na resolução dos sinais clínicos em pacientes com LMV. Tiabendazol, mebendazol e albendazol têm determinado melhora em $47 \%$ a $57 \%$ dos indivíduos tratados ${ }^{(16)}$. Uma possível explicação para a aparente baixa taxa de cura por essas drogas estaria relacionada ao fato dos benzimidazólicos agirem inibindo a polimerização da tubulina e à tendência das larvas de Toxocara a permanecerem quiescentes nos tecidos do hospedeiro por longos períodos antes de reassumir sua atividade migratória. Outros medicamentos não-derivados benzimidazólicos também têm demonstrado alguma eficácia, como a dietilcarbamazina e a ivermectina, porém com resultados menos expressivos ${ }^{(14)}$.

No tratamento da toxocaríase murina, vários anti-helmínticos têm sido usados (mebendazol, albendazol, fenbendazol e tiabendazol) com a finalidade de avaliar sua eficácia. Outras drogas como a ciclosporina e a betametasona também têm sido utilizadas ${ }^{(5,9,12,18,19)}$. Tem se demonstrado que o tiabendazol inibe o sistema de redução do fumarato dos músculos de $T$. canis e provoca imobilização das larvas, ocasionando o enfraquecimento progressivo destas neste nematódeo ${ }^{(1,6)}$. $\mathrm{O}$ mebendazol ocasiona a perda de microtúbulos do parasita ${ }^{(5)}$, apresentando atividade larvostática na fase hepatopulmonar e larvicida na fase miotrópica/neurotrópica da toxocaríase ${ }^{(6)}$. Em trabalhos realizados com ivermectina e o nemátode de vida livre Caenorhabditis elegans, Schaeffer e Haines(21) demonstraram que essa droga provoca imobilização dos vermes, induzindo uma paralisia tônica da musculatura, mediada pela potencialização direta dos canais de íons cloreto $(\mathrm{Cl})$ sensíveis à ivermectina. Isso acarreta aumento da permeabilidade da membrana celular aos $\mathrm{Cl}$, com hiperpolarização de nervos ou células musculares, resultando na morte do parasita ${ }^{(4,11)}$.
A maioria dos trabalhos avalia o efeito da quimioterapia mediante a recuperação de larvas nos tecidos do hospedeiro. Somente Cuéllar et al. ${ }^{(9)}$ e Bardón et al. ${ }^{(5)}$ estudaram a atividade quimioterápica do mebendazol por meio da deteç̧ão de anticorpos anti-Toxocara por técnicas imunológicas (ELISA), concluindo que a avaliação da quimioterapia por tal método é uma maneira válida para determinar a eficiência do tratamento sem as desvantagens apresentadas pela recuperação larvária dos vários tecidos digeridos.

Os objetivos deste trabalho foram: quantificar o número de larvas de $T$. canis recuperadas de camundongos com infecção experimental na fase crônica, após o tratamento com ivermectina, mebendazol ou tiabendazol, e determinar a presença de anticorpos anti- $T$. canis nos camundongos infectados e tratados com as drogas acima mencionadas.

\section{Material e método}

Foram utilizados 50 camundongos Balb/c com 6-8 semanas de idade. Quarenta foram infectados, por via oral, com 300 ovos larvados de T. canis. Após 30 dias de infecção (DPI) foram constituídos cinco grupos:

- grupo tox.: dez animais infectados, não-tratados;

- grupo A: dez animais infectados e tratados com ivermectina $(200 \mu \mathrm{g} / \mathrm{kg} / \mathrm{dia})$;

- grupo B: dez animais infectados e tratados com tiabendazol $(100 \mathrm{mg} / \mathrm{kg} / \mathrm{dia})$;

- grupo C: dez animais infectados e tratados com mebendazol (10mg/kg/dia);

- grupo controle: dez animais foram mantidos livres de infecção.

Todos os animais foram tratados, por via oral, com as drogas (obtidas comercialmente) durante cinco dias consecutivos. Os camundongos foram sangrados pelo plexo retro-orbitário aos 30, 50, 70, 90, 120, 150, 180 e 270 DPI e os soros foram processados pela técnica de ELISA para pesquisa de anticorpos da classe lgG, utilizando antígeno de excreção-secreção de $T$. canis preparado a partir de larvas em cultura, segundo técnica recomendada por De Savigny et al. ${ }^{(13)}$

Aos 270 dias pós-infecção, os animais foram sacrificados por deslocamento cervical e foram recuperadas larvas do sistema nervoso central (SNC), do fígado, dos pulmões e dos músculos, por digestão dos diversos órgãos com solução de ácido clorídrico a 5\%(23). 
Os resultados obtidos foram analisados por meio de teste estatístico não-paramétrico (Kruskal-Wallis), empregando-se nível de significância de $5 \%(p=0,05)$.

\section{Resultados}

A recuperação de larvas de $T$. canis, após digestão de SNC, fígado, pulmões e carcaça consta da Tabela, verificando-se diferença significativa entre o número médio de larvas recuperadas no grupo não-tratado e nos três grupos submetidos ao tratamento. Não foi observado, entretanto, qualquer diferença entre os resultados obtidos com as três drogas utilizadas.

Não foram notadas diferenças significativas na média das leituras das densidades ópticas nos soros dos camundongos do grupo controle não-tratado e dos três grupos submetidos a tratamento, os quais foram processados pelo teste ELISA IgG anti-Toxocara, conforme indica a Figura.

\section{Discussão}

O tratamento da toxocaríase humana com anti-helmínticos que possuam atividade larvicida ou larvostática tem sido recomendado pela maioria dos autores que abordaram a questão. Entretanto, algumas dúvidas persistem no que diz respeito à sua indicação. Alguns pesquisadores consideram que o tratamento anti-helmíntico somente deve ser utilizado em pacientes que, além de revelarem títulos significativos de anticorpos anti-Toxocara, apresentem sintomas e/ou sinais da doença $a^{(3,8)}$. A maior parte, contudo, recomenda o tratamento sempre que se evidencie a ocorrência de infecção, independentemente da presença de $\operatorname{sintomas}^{(16,17)}$.

A toxocaríase murina experimental tem sido, com freqüência, utilizada como modelo para a avaliação da atividade de anti-helmínticos na destruição ou na imobilização de larvas de $T$. canis(1, 6, 12, 14,15,20,22), com resultados variáveis, conforme a droga e o esquema terapêutico empregados.

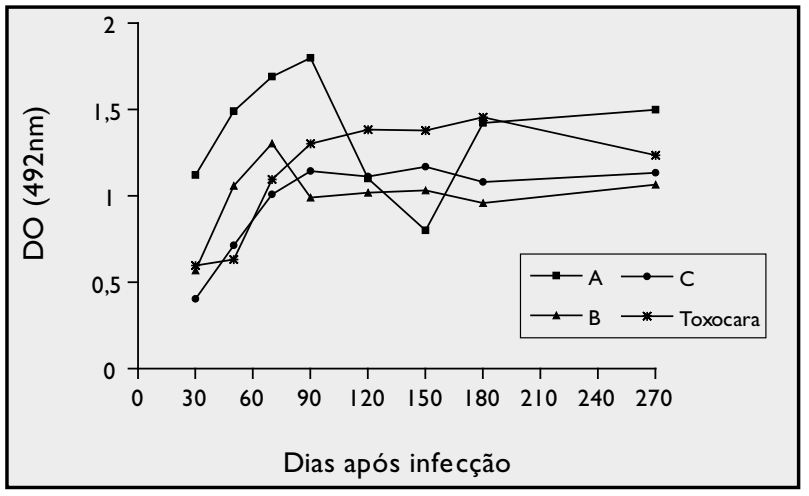

Figura - Dinâmica de anticorpos IgG anti-Toxocara em camundongos infectados por T. canis e tratados com ivermectina $(A)$, tiabendazol $(B)$ e mebendazol $(C)$

Outra questão ainda não completamente resolvida é a forma de avaliação das drogas utilizadas na terapêutica experimental da toxocaríase, na qual o modelo mais usado é o murino. A maioria dos autores utiliza a recuperação de larvas de $T$. canis, após digestão da carcaça e de alguns órgãos dos camundongos experimentalmente infectados ${ }^{(1,15,20,22)}$. Outros, entretanto, empregaram técnicas imunológicas $(5,9,10)$.

No presente trabalho procurou-se determinar a cinética de anticorpos lgG anti-Toxocara em camundongos experimentalmente infectados e tratados com tiabendazol, mebendazol e ivermectina, bem como a quantidade de larvas recuperadas após digestão ácida dos diferentes órgãos dos animais.

Os resultados do teste imunoenzimático (Figura) indicam que, aos 20 dias após tratamento (50 DPI), o nível de anticorpos anti-Toxocara da classe $\lg \mathrm{G}$ aumentou nos três grupos tratados, mantendo-se elevado ao longo do experimento até o $270^{\circ} \mathrm{DPI}$.

O aumento da densidade óptica observada nos soros dos camundongos tratados com as três drogas no $20^{\circ}$ dia após o início da administração das mesmas provavelmente se deve à maior estimulação do sistema imune, em razão da liberação de produtos metabólicos e da morte das larvas do nematódeo. Esse fato também foi verificado por Cuéllar et al. ${ }^{(9)}$, ao tratarem camundongos experimentalmente infectados por $T$. canis com mebendazol, porém em ocasião mais próxima à administração do anti-helmíntico.

\section{Tabela}

Grupo

$\mathbb{N}^{0}$ de animais

Toxocara

8

A (ivermectina)

$B$ (tiabendazol)

C (mebendazol)
Recuperação de larvas de $T$. canis de camundongos infectados tratados com ivermectina, tiabendazol e mebendazol e não-tratados, com 270 dias de infecção

No médio de larvas recuperadas

Desvio-padrão
147,3
82,7
24,3
13,35
21,88
10,7
20,12 
Como as três drogas anti-helmínticas foram administradas aos 30 dias após a infecção, a morte das larvas deve ter ocorrido no período em que se encontravam na fase miotrópica-neurotrópica e, provavelmente, com diminuição da sua atividade migratória. Assim, a elevação dos níveis de anticorpos anti-Toxocara, evidenciada nas amostras de soro colhidas no $20^{\circ}$ dia após tratamento $\left(50^{\circ} \mathrm{DPI}\right)$, reforça a hipótese de que essas drogas agem inclusive quando as larvas já se encontram encistadas, como defendem Fok et al. ${ }^{(15)}$, contrariamente à opinião de Bhatia et al..$^{(7)}$.

Em relação ao número total de larvas recuperadas dos camundongos (Tabela), observou-se decréscimo significativo (entre $75 \%$ e $80 \%$ ) nos animais dos grupos
A (tratados com ivermectina), B (com tiabendazol) e C (com mebendazol) quando comparados aos animais infectados e não-tratados, porém sem registro de cura parasitológica.

Os resultados obtidos mostram que ivermectina, mebendazol e tiabendazol apresentaram atividade semelhante contra larvas de $T$. canis, determinando significativa redução na carga parasitária, mas sem promover a cura parasitológica. A sobrevivência de pequena quantidade de larvas, encistada nos tecidos, revelou-se capaz de manter inalterada a resposta humoral, justificando a persistência de testes sorológicos positivos, por tempo prolongado, em pacientes submetidos a tratamento com essas drogas.

\section{Referências}

I.ABDEL-HAMEED,A.A. Effect of thiabendazole on the migration of Toxocara canis larvae in the mouse. J Parasitol, v. 70, n. 2, p. 226-3I, 1984.

2. ANARUMA FILHO, F. et al. Human toxocariasis: incidence among residents in the outskirts of Campinas, State of São Paulo, Brazil. Rev Inst Med Trop São Paulo, v. 45, n. 5, p. 293-4, 2003.

3. APT, W. Visceral larva migrans. Int J Parasitol, v. 17, n. I, p. I46, 1987.

4. ARENA, J. P. et al. The mechanism of action of avermectins in Caenorhabditis elegans: correlation between activation of glutamate-sensitive chloride current, membrane binding, and biological activity. J Parasitol, v. 8I, n. 2, p. 286-94, 1995.

5. BARDÓN, R. et al. Evaluation of mebendazole activity on experimental murine toxocariasis by immune complexes determination. J Vet Med B, v. 42, p. 235-46, 1995.

6. BARDÓN, R.; CUÉLLAR, C:;GUILLÉN, J. L. Evaluation by larval recovery of mebendazole activity in experimental murine toxocariasis. Int J Parasitol, v. 25, n. 5, p. 587-92, 1995.

7. BHATIA, V:; SARIN, S. K. Hepatic visceral larva migrans: evolution of the lesion, diagnosis, and role of high-dose albendazole therapy. Am J Gastroenterol, v. 89, n. 4, p. 624-7, 1994.

8. CAUMES, E.Treatment of cutaneous larva migrans and Toxocara infection. Fundamental and Clinical Pharmacology, v. 17, n. 2 p. 213, 2003.

9. CUÉLLAR, C. et al. Evaluation of chemotherapy in experimental toxocarosis by determination of specific immune complexes. J Helminthol, v. 64, p. 279-89, 1990.

10. CUÉLLAR, C. et al. Isotype specific immune responses in murine experimental toxocariasis. Mem Inst Oswaldo Cruz, v. 96, n. 4, p. 549-53, 2001.

I I. CULLY, D. F. et al. Cloning of an avermectin-sensitive glutamategated chloride channel from Caenorhabditis elegans. Nature, v. 37I, n. 20, p. 707-II, 1994.

12. DAFALLA,A.A.A study of the effect of diethylcarbamazine and thiabendazole on experimental Toxocara canis infection in mice. J Trop Med Hyg, v. 75, p. 158-9, 1972.
13. DE SAVIGNY, D. H.; VOLLER, A. ELISA for toxocariasis using larval secretory antigens. Trans R Soc Trop Med Hyg, v. 73, p. 106, 1978.

14. DELGADO, O.; BOTTO, C.; MATTEI, R. Effect of albendazole in experimental toxocariasis of mice. Ann Trop Med Parasitol, v. 83, n. 6, p. 621-4, 1989.

I5. FOK, E.; KASSAI,T. Toxocara canis infection in the paratenic host: a study on the chemosusceptibility of the somatic larvae in mice. Vet Parasitol, v. 74, n. 2-4, p. 243-59, 1998.

16. GLICKMAN, L.T.; MAGNAVAL,J.F.Zoonotic roundworm infections. Infect Dis Clin North Am, v. 7, n. 3, p. 717-32, 1993.

17.JACOB, C. M.A. et al. Clinical and laboratorial features of visceral toxocariasis in infancy. Rev Inst Med Trop São Paulo, v. 36, p. 19-26, 1994

18. LESCANO, S.A.Z. et al. Efeitos da ciclosporina A e betametasona na toxocaríase murina experimental. Rev Soc Bras MedTrop, v. 37, p. 22-4, 2004.

19. NICHOLAS,W. L;;STEWART,A. C.The action of benzimidazoles on the larval stage of Toxocara canis in the mouse. Ann Trop Med Parasitol, v. 73, n. I, p. 57-62, 1979.

20. SAMANTA, S.;ANSARI, M.Z. Anthelmintic effect of ivermectin, albendazole, fenbendazole and thiabendazole on larval Toxocara canis infection in mice. Indian J Anim Sci, v. 60, n. I0, p. I 195-6, 1990.

21. SCHAEFFER, J. M.; HAINES, H.W. Avermectin binding in Caenorhabditis elegans. Biochem Pharmacol, v. 38, n. 14, p. 2329-38, 1989

22. VIEIRA, M. et al. Avaliação da eficácia do ivermectin na larva migrans murina experimental. Rev Patol Trop, v. 22, n. I, p. |-8, 1993.

23. XI,W. G.; IIN, L.Z.A novel method for the recovery of Toxocara canis in mice. J Helminthol, v. 72, p. 183-4, 1998.

\begin{tabular}{l|l} 
& Endereço para correspondência \\
\hline & Pedro Paulo Chieffi \\
Instituto de Medicina Tropical de São Paulo \\
Av. Dr. Enéas de Carvalho Aguiar 470 - Prédio II \\
CEP 05403-000 - São Paulo-SP
\end{tabular}

